\title{
Study on the damage of semi rigid base asphalt pavement under high temperature condition
}

\author{
Le Sun ${ }^{1, a}$, Xiaojun $\mathrm{Li}^{2, \mathrm{~b},}$ Xuelian Wang ${ }^{3, \mathrm{c}}$ \\ ${ }^{1}$ School of Geology and Environment, Xi'an University of Science and Technology, \\ Xi'an, Shaanxi, 710054, China \\ ${ }^{2}$ School of Geology and Environment, Xi'an University of Science and Technology, \\ Xi'an, Shaanxi, 710054, China. \\ ${ }^{3}$ Guangzhou Maritime College, Guangzhou, Guangdong, 510725, China \\ aemail: 1140877567@qq.com, bemail: Ixjun@xust.edu.cn, 'email: 545093828@qq.com
}

Keywords: Finite element method; asphalt pavement potential damage index; ratting

\begin{abstract}
Rutting, Top-Down cracking and bottom-up cracking are considered as major damage phenomena in pavement structure. In this study, the Drucker-Prager (D-P) criterion is adopted to analyze the pavement structure on Ji-Qing highway. Three dimensional finite element model with double rounds uniform load is established. The concept of asphalt pavement potential damage index (APPDI) is put forward in the light of the stress composition forms. The results show that: Firstly, the main failure mode of this mode is rutting in the early stage under the high temperature. Secondly, combined with the Mohr circle and the location in the pavement structure, APPDI can accurately judge the damage form of asphalt pavement, which provides a theoretical basis for the interpretation of pavement failure mechanism and optimization of pavement design.
\end{abstract}

\section{Introduction}

Mechanics analysis of pavement structure is a traditional topic in road engineering study, and a lot of works have been carried out by Hao Liu.[1],James et al.[2],and Hasan Ozer.[3]. Rutting, Top-Down cracking and bottom-up are considered as major damage phenomena in pavement structure. Finite element method (FEM) can predict pavement response to vehicular loading.

This paper attempts to use the Drucker-Prager (D-P) criterion to analyze the pavement structure. The double rounds uniform load calculation model of multi-layer semi rigid base asphalt pavement is established in this paper. Asphalt Pavement Potential Damage Index (APPDI), for asphalt pavement with multiple damage phenomena is presented. The damage mechanism of asphalt pavement and the complexity of pavement structure stress state have been discussed to provide assistance for the design of the pavement structure.

\section{THEORETICAL BACKGROUND}

Drucker-Prager stress is used as a criterion in determining the onset of failure in geotechnical materials [4]. The failure criterion state that the vector radius of an arbitrary point on $\pi$ plane $\mathrm{r} \pi$ should be less than the vector radius of yield curve of an arbitrary point on $\pi$ plane $r \sigma$. In the inequality form, the criterion is

$$
r_{\pi} \leq r_{\sigma}
$$

The $\pi$ plane position and the yield curve size of each point are different because the I1 and J2 of an arbitrary node are different in the pavement structure. Since the projection of D-P criterion yield curve on plane is always round, we define the Asphalt Pavement Potential Damage Index (APPDI) to reflect the fatigue state of each point effectively. The formula signifies as Eq. (2).

$$
\begin{aligned}
& \text { APPDI }=\frac{\mathrm{r}_{\pi}}{r_{\sigma}}=\frac{\sqrt{\left(\left(\sigma_{1}-\sigma_{2}\right)^{2}+\left(\sigma_{1}-\sigma_{3}\right)^{2}+\left(\sigma_{3}-\sigma_{2}\right)^{2}\right)}}{\sqrt{6} * \sqrt{\left(k+\alpha^{*}\left(\sigma_{1+} \sigma_{2}+\sigma_{3}\right)\right)}} \\
& \text { Where: } \alpha=\frac{1}{\sqrt{3}} \frac{\sin \varphi}{\sqrt{3+\sin \varphi^{2}}}, k=\frac{\sqrt{3} c \cos \varphi}{\sqrt{3+\sin ^{2} \varphi}}
\end{aligned}
$$


$c$ is the value of cohesion and $\varphi$ is the value of internal friction angle.

\section{MODEL CONSTRUCTION}

To compare with the previous calculation examples, a three-dimensional double rounds uniform load finite element model is developed to simulate the behavior of Ji-Qing Highway in this paper. The calculation adopts the standard axle load according to Highway Asphalt Pavement Design Specification(2006). The calculation parameters are shown in Table 1[5].

Table 1 Standard axle calculation parameters

\begin{tabular}{cc}
\hline Name & BZZ-100 \\
\hline The standard axle (P) & $100 \mathrm{KN}$ \\
The contact pressure of the circle contact area (p) & $0.70 \mathrm{MPa}$ \\
The equivalent circle radius of the circle contact area (r) & $0.1065 \mathrm{~cm}$ \\
The space interval between tires' center (d) & $0.3195 \mathrm{~cm}$ \\
\hline
\end{tabular}

Table 2 supplies the thicknesses and materials used in the model for analysis. The asphalt concrete layers are the main contribution to the structural capacity of the pavement[6].

Table 2 Pavement structure parameters

\begin{tabular}{ccccc}
\hline \multicolumn{2}{c}{ Layer } & $h_{i} / \mathrm{cm}$ & $E_{i} / \mathrm{MP} \mathrm{a}$ & $v_{i}$ \\
\hline \multirow{2}{*}{$\begin{array}{c}\text { Asphalt } \\
\text { layer }\end{array}$} & Surface course & 4 & 350 & 0.35 \\
& Middle course & 5 & 500 & 0.35 \\
& Binder course & 6 & 700 & 0.35 \\
& Base & 34 & 1500 & 0.35 \\
Sub-base & 18 & 550 & 0.2 \\
Sub-grade & & 35 & 0.4
\end{tabular}

Based on suggestions from the document literature, it decides to make the model 10-meters long, 10-meters wide and 9-meters deep. In this study, the pavement structure is assumed to be an elastic body, the contact conditions among pavement structure layers are completely continuous. Infinite element boundaries are placed at both ends of left and right, on both sides of front and back, and at the bottom of the model to simulate the influence of the pressure area. The full 3D finite element model is shown in Figure 1.

\section{Analysis based on the distribution}

All nodes of the asphalt layer are selected in this model. These nodes were calculated according to the formula (2) and the most dangerous nodes were chosen, then these chosen nodes' space distribution order and the principle stresses are shown in Fig. 2. 


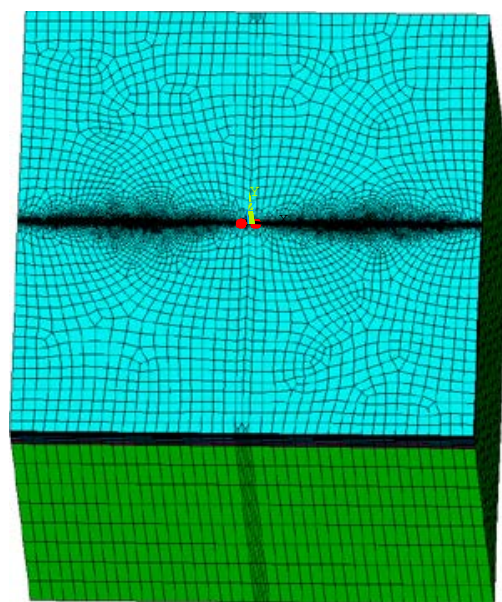

Figure 1. The full three-dimensional finite element model
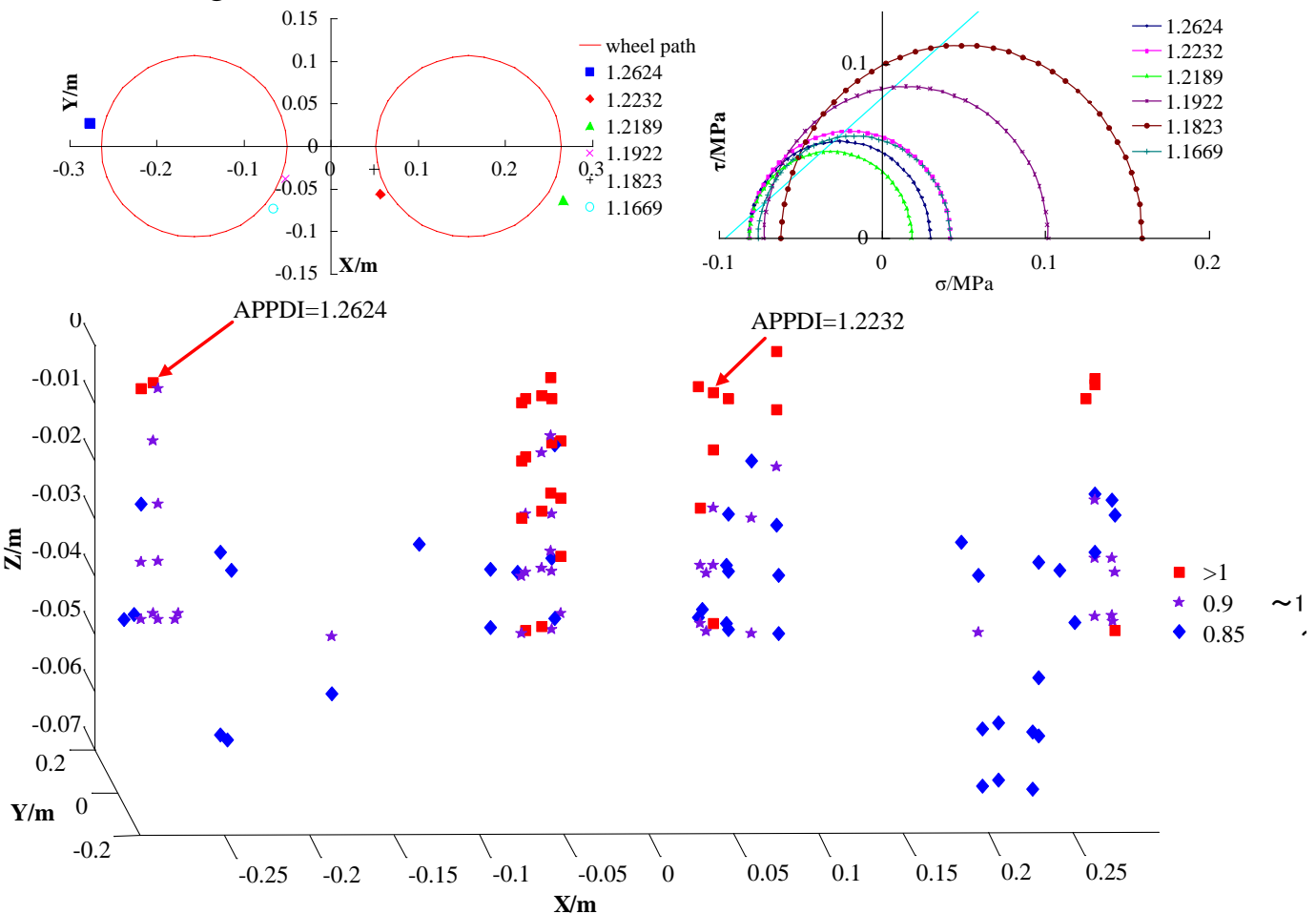

Figure 2. The space distribution and the principle stresses of the dangerous nodes

Figure 2 shows that the regions are mainly distributed in the middle of the two rounds in the up-layer and the top of the middle-layer. The maximum value of APPDI is 1.2624 , in which the $\sigma 1$ equals $0.0291 \mathrm{MPa}, \sigma 3$ equals $-0.0822 \mathrm{MPa}$. The stress state is tension-compression composite shear stress. It is located $1 \mathrm{~cm}$ of the tire loading on the surface and the failure mode is deduced as rutting.The second value of APPDI is $1.2232 \mathrm{MPa}$, in which the $\sigma 1$ equals $0.0414 \mathrm{MPa}, \sigma 3$ equals $-0.0815 \mathrm{MPa}$. The stress state is tension-compression composite shear stress.It is located $1 \mathrm{~cm}$ of the tire loading on the surface (area B) and the failure mode is deduced as rutting.

\section{Analysis of the longitudinal profile of the asphalt layer}

All nodes in $y=0$ profile in the mode are selected. These nodes are calculated according to the formula (2) and the most dangerous 200 nodes are chosen, The order of their appearance are analyzed and shown in Figure 3. 


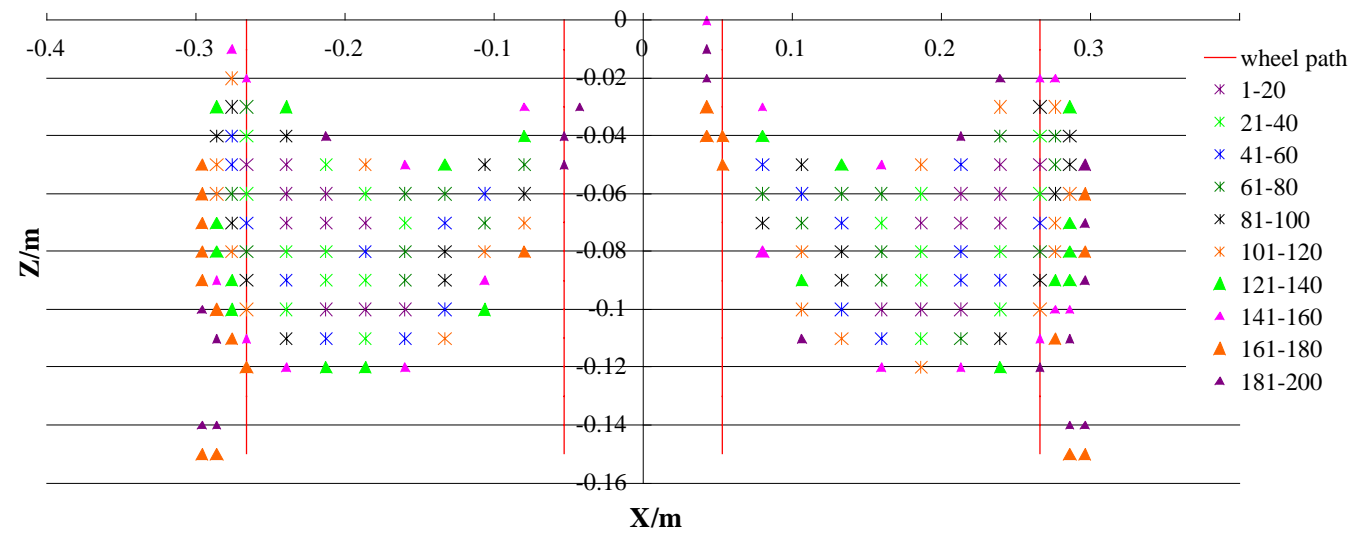

Fig. 3. The distribution order of the forward forward direction $y=0$ section plane dangerous nodes

As we can be seen from the Figure 3, the dangerous nodes mainly appeared at the middle of asphalt layer under the tire loading. Under the tire loading, the dangerous nodes began at the middle of the asphalt layer and then develop upside so as to generate the rutting damage. The distribution and development rules outside the wheel path are the same as the counterpart under the tire loading.

\section{Conclusion}

The mechanics analysis of Ji-Qing Highway which is a semi rigid base pavement structure was studied in this study. The study is summarized as follows:

1) The APPDI was determined as the evaluation index of pavement structure damage under complex stress condition. The main failure mode of Ji-Qing highway is rutting in the early stage under the high temperature.

2) The most dangerous nodes appear mainly at the asphalt layer between rounds away from round edge 0 to $2 \mathrm{~cm}$ and under the tire loading in this example model. The principal stresses are tensile and compressive stress. The tensile-compression composite shear failure theory can be used as the unified mechanics model of the early damage of asphalt pavement structure.

3) APPDI can be used as the parameters of the unify of the pavement structures' mechanical properties and material design.

\section{References}

[1] Hao Liu. Strength Characteristics of Asphalt Mixture Based on Three-direction Independent Load Under Low Temperature and Application[D]. Changsha University of Science \& Technology, 2013.

[2] James W. Maina, Yoshiaki Ozawa and Kunihito Matsui. Linear Elastic-analysis of Pavement Structure Under Non-circular Loading, Road Materials and Pavement Design, 2012 13:3, 403-421.

[3] Hasan Ozer. Development of Domain Integral and Generalized Finite Element Methods for Three-dimensional Analysis of Near Surface Cracking in Flexible Pavement. University of Illinois at Urbana-Champaign, 2011.

[4] Zheng Ying-ren, Zhang Liang. Geotechnical plastic mechanics(CBI press, CHINA).In Chinese. 2005

[5] Industry standard of the People's Republic of China. Highway Asphalt Pavement Design Specification[S]. Beijing: people's traffic press, JTG D50-2006

[6] Li-jun Sun. Asphalt Pavement Structural Behavior Theory[M]. Beijing: people's traffic press. 2005. 